The use of micro computed tomography to ascertain the morphology of bloodstains on fabric.

Dicken, L. ${ }^{1}$, Knock, C. ${ }^{1}$, Beckett, S. ${ }^{2}$, de Castro, T. C. ${ }^{3}$, Nickson, T. ${ }^{4}$, Carr, D. J. ${ }^{1}$

Authors' addresses

${ }^{1}$ Centre for Defence Engineering, Cranfield University at the Defence Academy of the United Kingdom, Shrivenham, SN6 8LA, United Kingdom.

${ }^{2}$ Cranfield Forensic Institute, Cranfield University at the Defence Academy of the United Kingdom, Shrivenham, SN6 8LA, United Kingdom.

${ }^{3}$ Sir John Walsh Research Institute, University of Otago, Dunedin, 9054, New Zealand.

${ }^{4}$ LGC Forensics, Culham, Oxfordshire, OX14 3ED.

\title{
Communicating Author
}

Dr. C. Knock, Centre for Defence Engineering, Cranfield University at the Defence Academy of the United Kingdom, Shrivenham, SN6 8LA, United Kingdom.

Telephone: +44 (0)1793 785335

Email: c.knock@cranfield.ac.uk 


\section{Abstract}

Very little is known about the interactions of blood and fabric and how bloodstains on fabric are formed. Whereas the blood stain size for non-absorbent surfaces depends on impact velocity, previous work has suggested that for fabrics the blood stain size is independent of impact velocity when the drop size is kept constant. Therefore, a greater understanding of the interaction of blood and fabric is required. This paper explores the possibility of using a micro computed tomography (CT) scanner to study bloodstain size and shape throughout fabrics. Two different fabrics were used: $100 \%$ cotton rib knit and $100 \%$ cotton bull drill. Bloodstains were created by dropping blood droplets from three heights; $500 \mathrm{~mm}, 1000 \mathrm{~mm}$ and $1500 \mathrm{~mm}$. Results from the CT scanner clearly showed the bloodstain shape throughout the fabric. The blood was found to form a diamond shaped stain, with the maximum cross-sectional area $0.3 \mathrm{~mm}$ to $0.5 \mathrm{~mm}$ below the surface. The bloodstain morphology depended on both the impact velocity and fabric structure.

\section{Keywords}

- Wicking

- Wetting

- Absorbent surfaces

\section{Key Messages}

- The use of the micro CT scanner to detect blood in fabric

- Size of bloodstain in fabric initially increases with depth

- Bloodstain forms a diamond shape in the fabric

\section{Introduction}

When blood hits a surface, a bloodstain is formed. Bloodstains are important to forensic science as, when present at the scene of a crime, they can help to provide important information on the character, number and chain of events which occurred (Karger et al. 2008). The main bloodstain is known as the parent bloodstain (SWGSTAIN 2014). Spines may form, which are linear characteristics around the circumference of the bloodstain. These are created when the surface tension can no longer hold the bloodstain as an integral entity (Bevel and Gardner 2008). Satellite stains can also be formed. These are separate bloodstains formed by secondary droplets, which detach when the large drop impacts the surface (Bevel and Gardner 2008). The formation of bloodstains on less- and nonabsorbent surfaces such as glass, stainless steel, laminate (Hulse-Smith et al. 2005), drywall and wood (Hulse-Smith and Illes 2007) and paper (Knock and Davison 2007) has been extensively reported. The aim of such experiments was to ascertain the drop diameter and velocity from variables such as parent stain area and number of spines. If the impact velocity is known, it is then possible to include the effect of gravity on the flight of the droplet and hence more accurately estimate the position of the source of the droplet (Knock and Davison 2007). When a non-absorbent surface is impacted higher velocity impact of blood droplets result in larger bloodstains and more spines (Hulse-Smith and Illes 2007, Knock and Davison 2007).

There is a paucity of information in the literature regarding the interaction of blood and absorbent surfaces, such as fabrics. Reported work has focused on the visible bloodstain on the fabric surface, 
treating it in much the same way as a bloodstain on a non-absorbent surface by looking at, for example, the number of satellite bloodstains or the parent stain area (e.g. White 1986, Karger et al. 1998, de Castro et al. 2013). The scarcity of literature in this area does not correlate with the importance of understanding bloodstains on fabric. When bloody clothing is examined following a crime, there is a need to be able to distinguish between the clothing worn by the assailant and a bystander. In Indiana v. Camm (2004) blood spatter which was found on the defendants clothing was believed by four prosecution expert witnesses to be consistent with high-velocity impact spatter. However, four experts for the defence stated that it was instead consistent with transfer stains, caused by the defendant finding the bodies rather than committing the murders. A greater understanding of the interaction of blood and fabrics would prevent situations such as this from arising.

In contrast with non-absorbent surfaces, the size of the parent bloodstain on fabrics is not reportedly affected by impact velocity when the drop size is kept constant (e.g. de Castro et al. 2013). A greater understanding of the interaction of blood and fabric, both in terms of the internal morphology of the bloodstain and the mechanisms by which the blood is soaking in to the fabric is required. Merely assessing bloodstains on the surface of a fabric as with bloodstains on nonabsorbent surfaces may not provide sufficient understanding of these mechanisms.

The movement of liquids into and through a fabric has to be understood with reference to wetting and wicking, as this will allow a greater understanding to be gained of why the blood soaks into the fabric. These two mechanisms are well understood in textile science, generally in the context of the movement of water and water-vapour into and through a fabric. Wetting is the displacement of the solid-air interface with the solid-liquid interface. The surface energy of a liquid would usually keep a drop of that liquid in a spherical shape. If this energy is overcome by the attractive forces between the liquid molecules and the surface on which the liquid is placed, wetting occurs (Kissa 1996). Wetting is a dynamic and complex process in a fibrous assembly. The surface fibres must be wetted (Kissa 1996) before the liquid can then be transported through the inter-fibre and inter-yarn pores by means of capillary action, known as wicking (Patnaik et al. 2006). Wicking can only occur when a wetted material has capillary spaces in between the fibres (Patnaik et al. 2006).

Wicking and wetting mechanisms are beginning to be considered within the context of blood on fabrics (de Castro et al. 2015). It has been shown that the fibre content within a plain woven fabric affects the resultant parent stain area, and therefore most likely the wetting and wicking properties. A cotton/ polyester blend was found to result in larger parent stain areas than either $100 \%$ cotton or $100 \%$ polyester, possibly owing to larger inter-fibre pore-size. $100 \%$ polyester produced larger stains than $100 \%$ cotton, most likely owing to the continuous polyester fibres producing capillary action, wicking the blood along the fibres but not into them (de Castro et al. 2015). As wetting and wicking will only occur on absorbent surfaces they therefore need to be treated differently to non-absorbent surfaces.

Thus a greater understanding of the internal morphology of the bloodstain is required to inform the mechanisms by which blood moves through a fabric's structure. The aim of the work summarised in this paper was to investigate the use of a micro computed tomography (CT) scanner to examine the morphology of the bloodstain inside fabrics. 


\section{Materials and methods}

\section{Materials}

Two fabric specimens were used in this research. They were i) $100 \%$ cotton rib knit fabric and ii) 100\% cotton bull drill (a woven fabric) (de Castro et al. 2013). In the work of de Castro et al. (2013), bloodstains were created on each fabric specimen by dropping a single blood drop from heights of i) $500 \mathrm{~mm}$, ii) $1000 \mathrm{~mm}$ and iii) $1500 \mathrm{~mm}$; five specimens of each fabric / height combination were used (de Castro et al. 2013). The three heights resulted in slightly different impact velocities for the two fabrics. For rib knit the mean impact velocities were: i) $3.2 \mathrm{~ms}^{-1}$, ii) $4.5 \mathrm{~ms}^{-1}$ and iii) $5.3 \mathrm{~ms}^{-1}$; for the bull drill they were i) $2.9 \mathrm{~ms}^{-1}$ ii) $4.2 \mathrm{~ms}^{-1}$ and iii) $5.0 \mathrm{~ms}^{-1}$. It has previously found to be the case that the effects of air resistance need to be taken into consideration when calculating velocity from drop height (Adam 2012). Therefore, as the mean drop diameter for the rib knit was $4.1 \mathrm{~mm}$ (s.d. = $0.01 \mathrm{~mm}$ ), but for the bull drill it was $3.4 \mathrm{~mm}$ (s.d. $=0.01 \mathrm{~mm})$, this is the most likely explanation for the differences in the velocities between the two fabrics. Velocity and blood drop diameter were consistent for each height for each fabric excepting one replicate which was removed from the current analysis. A technical drawing of the resultant specimens can be seen in figure 1.

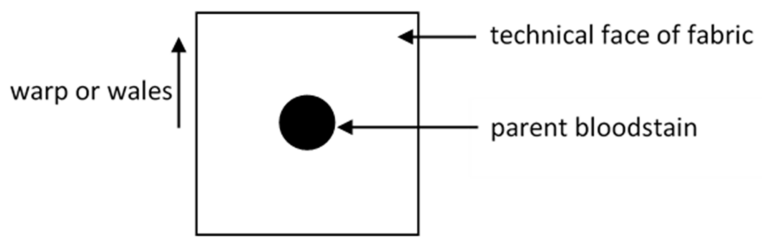

Fig $1 \mathrm{a}$

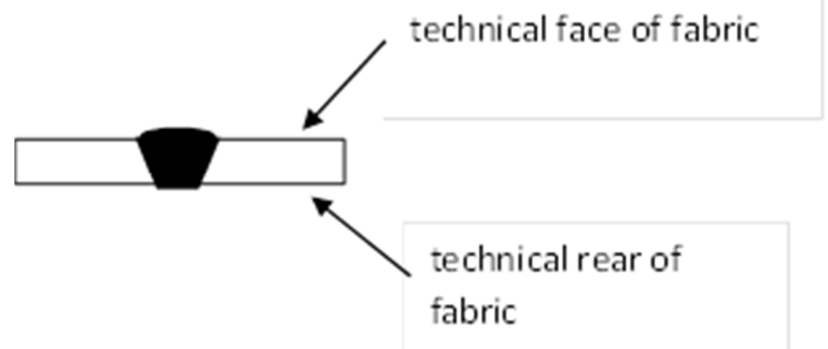

Fig 1b

Figure 1: a technical drawing of the resultant specimens, indicating the direction of the warp (woven) and wales (knitted) (fig 1a), and a possible cross-section of a specimen, indicating the two faces of the fabrics (1b).

\section{Method}

The specimens, for which previously only the external visible stain had been analysed (de Castro et al. 2013), were examined using a Nikon XTH225 micro CT scanner ${ }^{1}$, with an Open Tube UltraFocus Reflection Target X-Ray source, a Tungsten target, a max kV of 225 and power rating of 225W. The xray spot size was $3 \mu \mathrm{m}$, with a geometric magnification of $>150 x$ and a Varian 2520 flat panel detector (Nikon Metrology 2010)

The micro CT scanner exploited the difference in density between the higher density dried blood and the lower density air-filled fabric. The two fabrics were analysed using different voltage (kV), current $(\mu \mathrm{A})$ and exposure (ms) settings to optimise contrast; the two fabrics were not compared to each other. This difference was due to the differences in the structure of the fabrics used in the work (knits are typically between $85-95 \%$ air whilst tight woven fabrics such as drills are typically between

\footnotetext{
${ }^{1}$ Nikon Metrology UK, Tring Business Centre, Icknield Way, Tring, Hertfordshire, HP23 4JX, UK.
} 
60-90\% air (Schneider and Holcombe 1988)). The samples were analysed between 30 - 35kV, 30 $330 \mu \mathrm{A}$ and $500-1000 \mathrm{~ms}$ exposure.

Scanning data was manually reconstructed using $\mathrm{CT} \mathrm{Pro}^{2}$, and then two-dimensional and threedimensional data were gathered using VGStudio $\mathrm{Max}^{3}$. The cross-sectional data were saved at $0.1 \mathrm{~mm}$ intervals in the vertical $(z)$ direction. The interval of $0.1 \mathrm{~mm}$ was decided upon to be able to visualise the bloodstain at small intervals without having an excessive number of cross-sections (figure 2). The data was then imported into ImageJ $^{4}$ to measure i) area ii) length in the $y$ (wale or warp) direction iii) length in the $\mathrm{x}$ (course or weft) direction. The built-in tools in ImageJ were used for each of these measurements. The area was measured using a freehand drawing tool around the external edge of each parent stain.

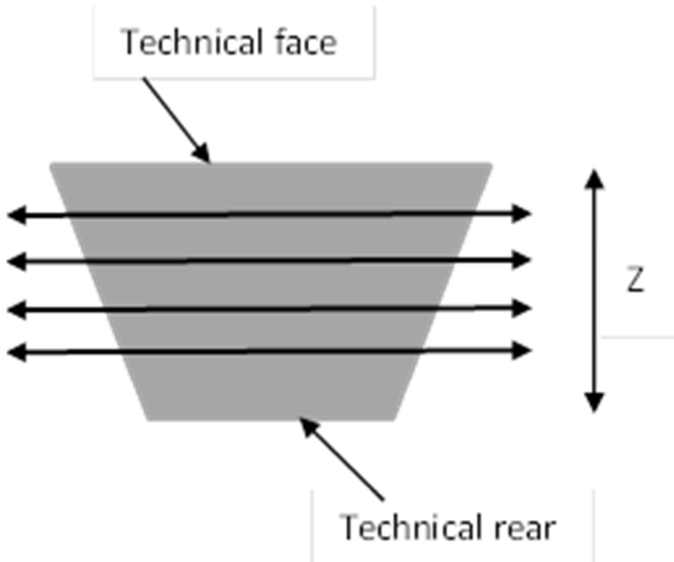

2a

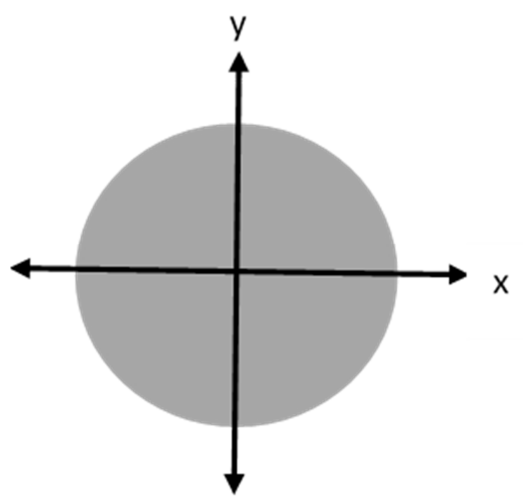

2b

Figure 2: the direction of the measurements taken from the bloodstain. The area measurements were taken on the cross-sections marked in figure $2 a$ from the technical face to the technical rear in direction $z$. The resultant images were approximately circular, as seen in figure $2 b$, and measurements were taken in the $y$ (wale or warp) direction and $x$ (course or weft) direction on the cross-section with the largest area.

To determine whether the impact velocity had a statistically significant effect on the area and the length in the $y$ (wale or warp) and $x$ (course or weft) directions of the bloodstain an analysis of variance (ANOVA) and Tukey's HSD test (IBM SPSS statistics version 22) was carried out. To ensure that these statistical tests were viable, equality of variances and normality of data were checked.

\footnotetext{
${ }^{2}$ CT Pro is an offline 3D computer tomography reconstruction programme (Metris 2008).

${ }^{3}$ VGStudio Max is high-end software for the visualisation and analysis of CT data (Volume Graphics 2014).

${ }^{4}$ ImageJ is a public domain Java image processing programme (http://imagej.nih.gov/ij/docs/intro.html accessed 20th Jan 2015)
} 


\section{Results}

\section{General Observations}

Figure 3 shows a typical cross-section from the micro CT in the z-direction of the bloodstains formed on the rib knit and bull drill fabrics. From these images it is possible to see the blood-soaked areas and blood-void areas (labelled $A$ in figure 3), the latter of which are most likely the air spaces between the yarns. There are more of these voids in the knit fabric (3a) than the bull drill (3b). It is also possible to see some variation in the intensity of the blood, with the external edges having a brighter colouration (labelled B in figure 3), suggesting denser blood in these areas. There is a possibility this is caused by the 'coffee-ring' effect. This is when the stain cannot shrink during drying, causing liquid evaporating from the edge to be replaced by liquid from the interior of the stain; hence, much of the dispersed material within the stain ends up at the edge (Deegan et al. 1997). This higher concentration of particulates would account for the brighter colouration seen in the CT scanner.

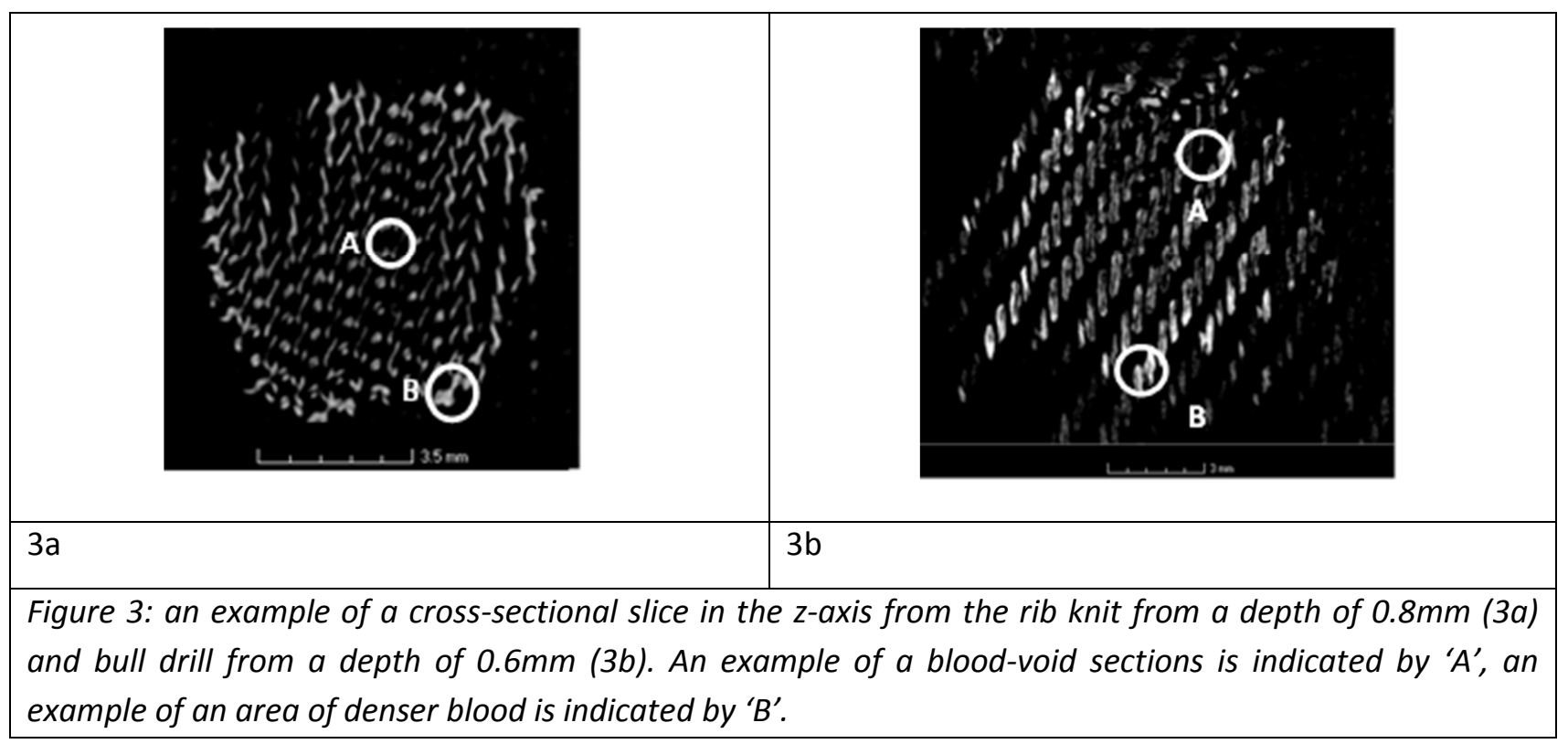

\section{Bloodstain Area}

The variation of the area with depth (z-direction) for each impact velocity is given in figure 4 for the rib knit and figure 5 for the bull drill fabric. For both fabrics and all impact velocities the bloodstain initially showed an increase in area with depth. The maximum area is reached between $0.3 \mathrm{~mm}$ and $0.5 \mathrm{~mm}$ below the technical face (figure 4, 5 and 6). Thereafter the mean area decreases with depth towards the technical rear of the fabric.

The coefficient of variation (CV) for each cross-sectional area through the fabrics varied. For both fabrics at all velocities the CV was smaller (between 2 and 11\%) at the centre of the bloodstain in the z-direction, between $0.5 \mathrm{~mm}$ and $0.7 \mathrm{~mm}$ from the technical face. This suggested there was more 
variation in the area of the bloodstain towards the technical face and the technical rear of the fabric, than there was in the middle of the bloodstain in the z-direction.

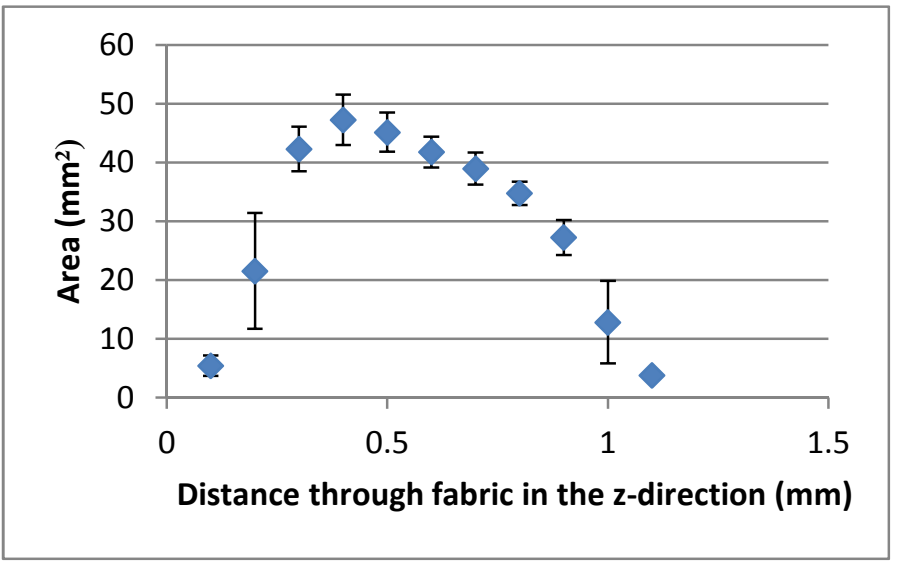

Fig 4a: the rib knit from $3.2 \mathrm{~ms}^{-1}$

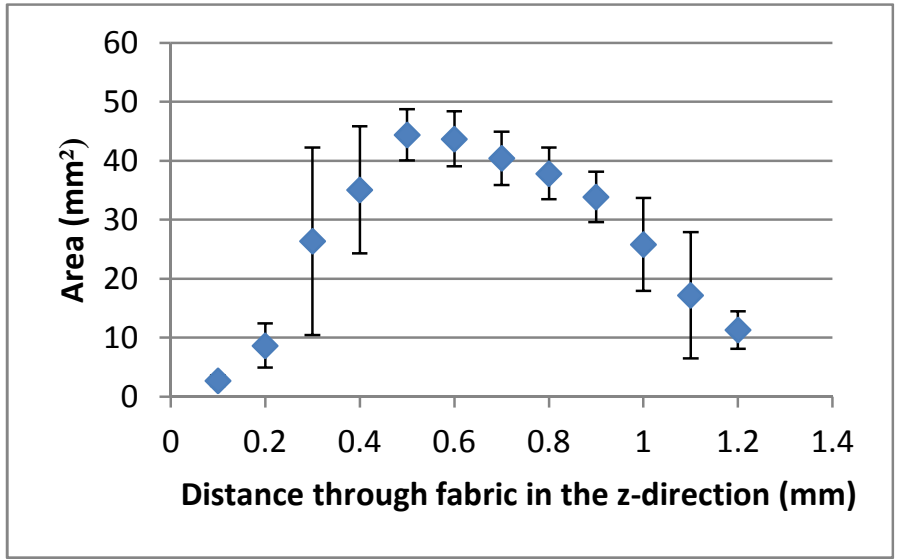

Fig $4 \mathrm{~b}$ : the rib knit from $4.5 \mathrm{~ms}^{-1}$

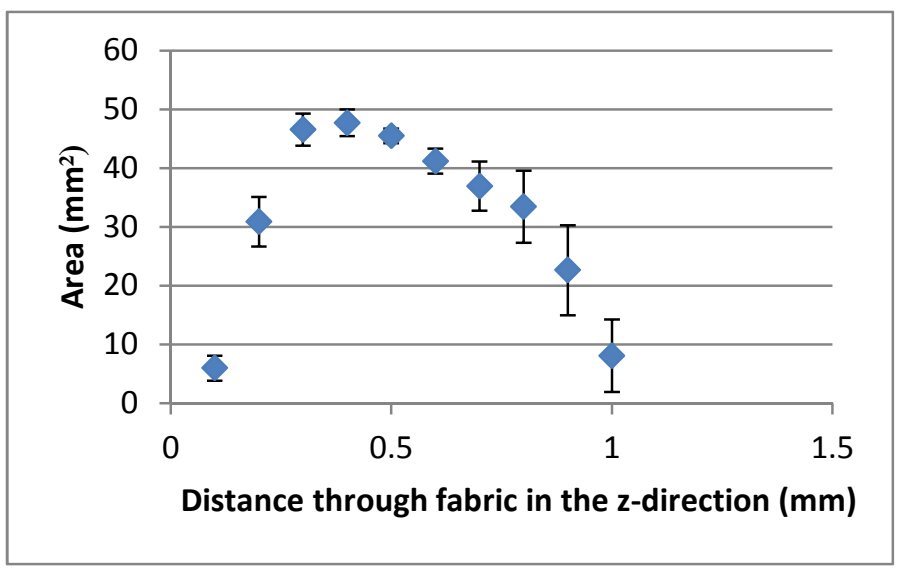

Fig 4c: the rib knit from $5.3 \mathrm{~ms}^{-1}$

Figure 4: The mean and standard deviation of the area of the parent bloodstain for cross-sections taken every $0.1 \mathrm{~mm}$ throughout the depth of the bloodstain in the z-direction for three velocities $\left(3.2 \mathrm{~ms}^{-1}, 4.5 \mathrm{~ms}^{-1}\right.$ and $\left.5.3 \mathrm{~ms}^{-1}\right)$ on rib knit fabric. 


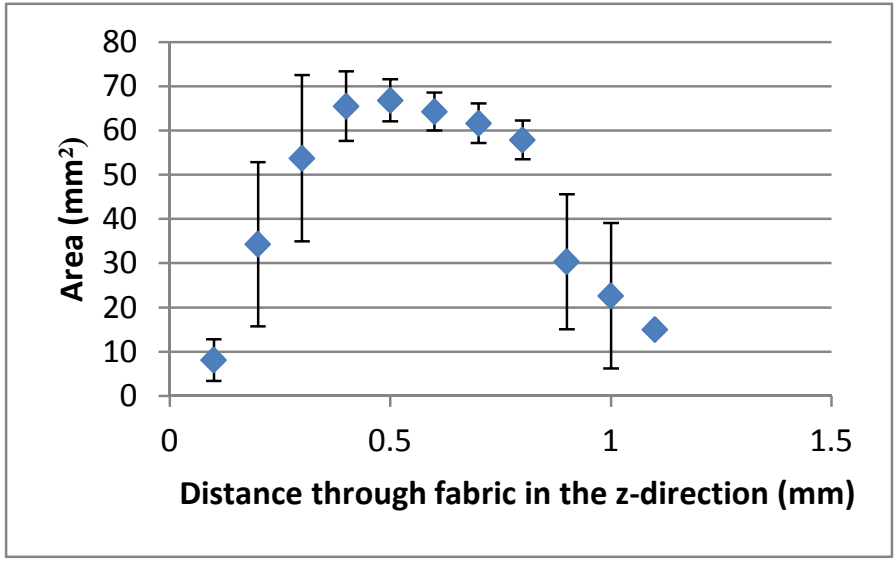

Fig 5a: the bull drill from $2.9 \mathrm{~ms}^{-1}$

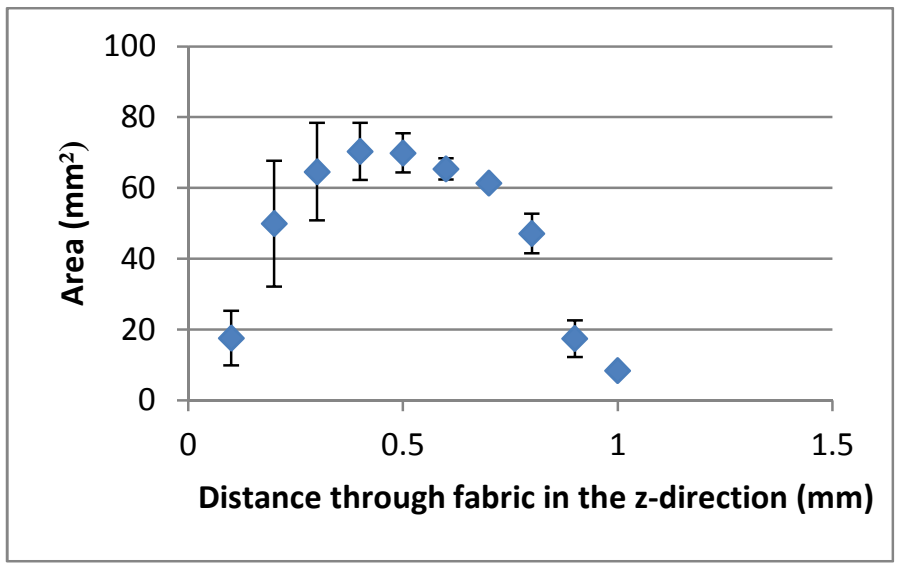

Fig $5 b$ : the bull drill from $4 \cdot \mathrm{ms}^{-1}$

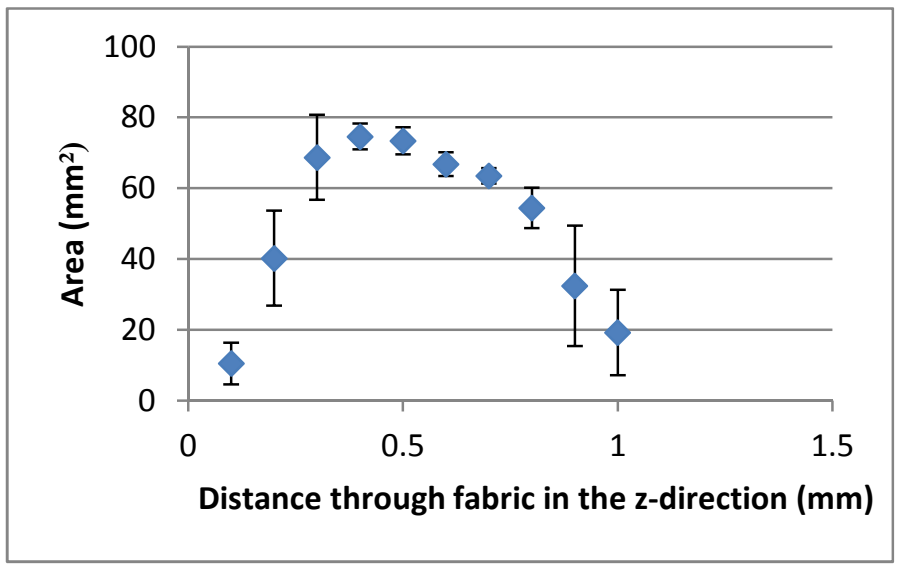

Fig 5c: the bull drill from $5.0 \mathrm{~ms}^{-1}$

Figure 5: The mean and standard deviation of the area of the parent bloodstain for cross-sections taken every $0.1 \mathrm{~mm}$ throughout the depth of the bloodstain in the z-direction for three velocities $\left(2.9 \mathrm{~ms}^{-1}, 4.2 \mathrm{~ms}^{-1}\right.$ and $\left.5.0 \mathrm{~ms}^{-1}\right)$ on bull drill fabric. 


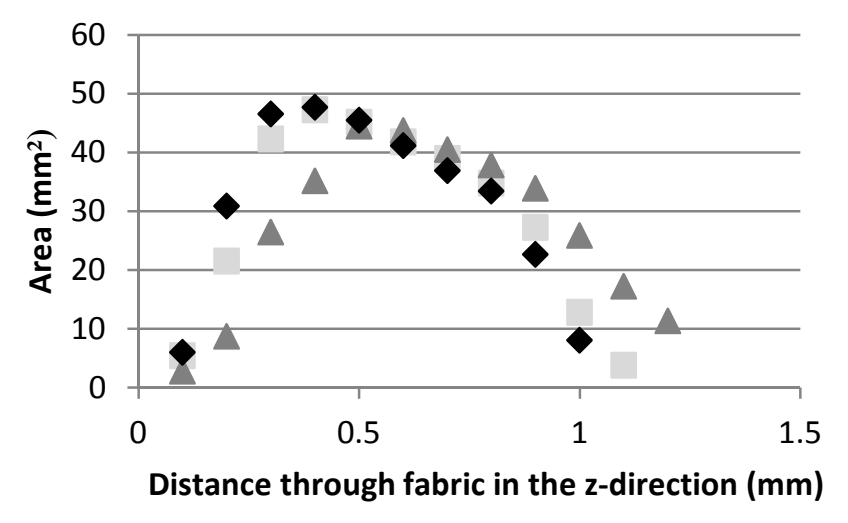

Fig 6a: the mean area for all impact velocities for the rib knit $\left(3.2 \mathrm{~ms}^{-1}=\square, 4.5 \mathrm{~ms}^{-1}=\Delta, 5.3 \mathrm{~ms}^{-1}=\bullet\right)$

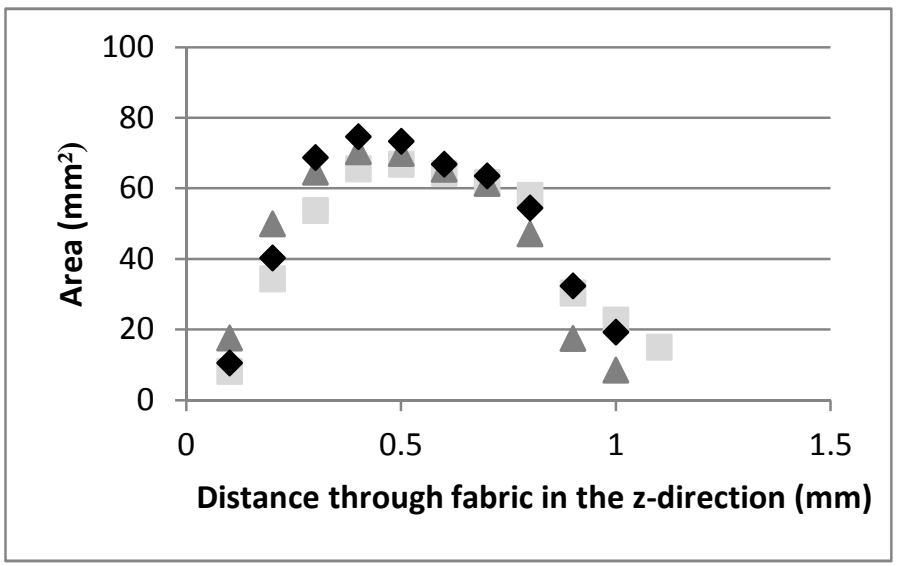

Fig 6b: the mean area for all impact velocities for the bull drill $\left(2.9 \mathrm{~ms}^{-1}=\square, 4.2 \mathrm{~ms}^{-1}=\Delta, 5.0 \mathrm{~ms}^{-1}=\bullet\right)$

Figure 6: The mean of the area of the parent bloodstain for cross-sections taken every $0.1 \mathrm{~mm}$ throughout the depth of the bloodstain in the z-direction for three velocities for both rib knit and bull drill fabrics.

The impact velocity affected the area of the bloodstain throughout the thickness of the fabric (i.e. in the z-direction, figure 2a).

Bloodstains formed on the rib knit fabric from the middle impact velocity of $4.5 \mathrm{~ms}^{-1}(1000 \mathrm{~mm})$ produced the smallest maximum area at the deepest point into the fabric (i.e. further away from the technical face of the fabric). The fastest impact velocity of $5.3 \mathrm{~ms}^{-1}(1500 \mathrm{~mm})$ and slowest impact velocity of $3.2 \mathrm{~ms}^{-1}(500 \mathrm{~mm})$ both produced larger maximum areas at a shallower depth than the middle velocity (figure $4,6 a$ ). 

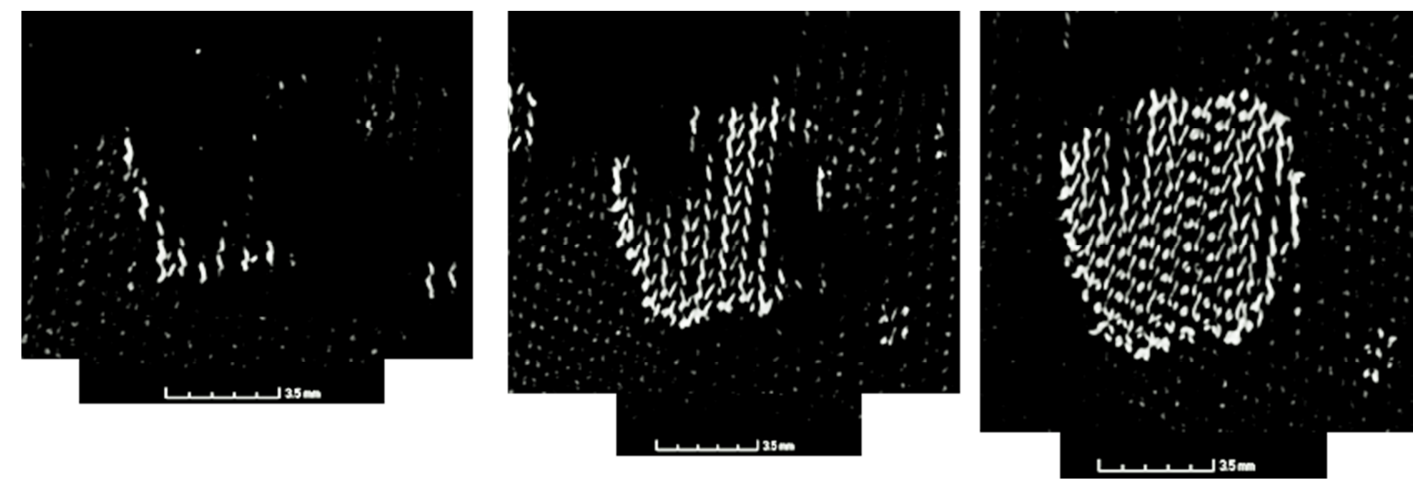

Figure 7a: the first three cross-sections in the z-direction for a specimen from $3.2 \mathrm{~ms}^{-1}$
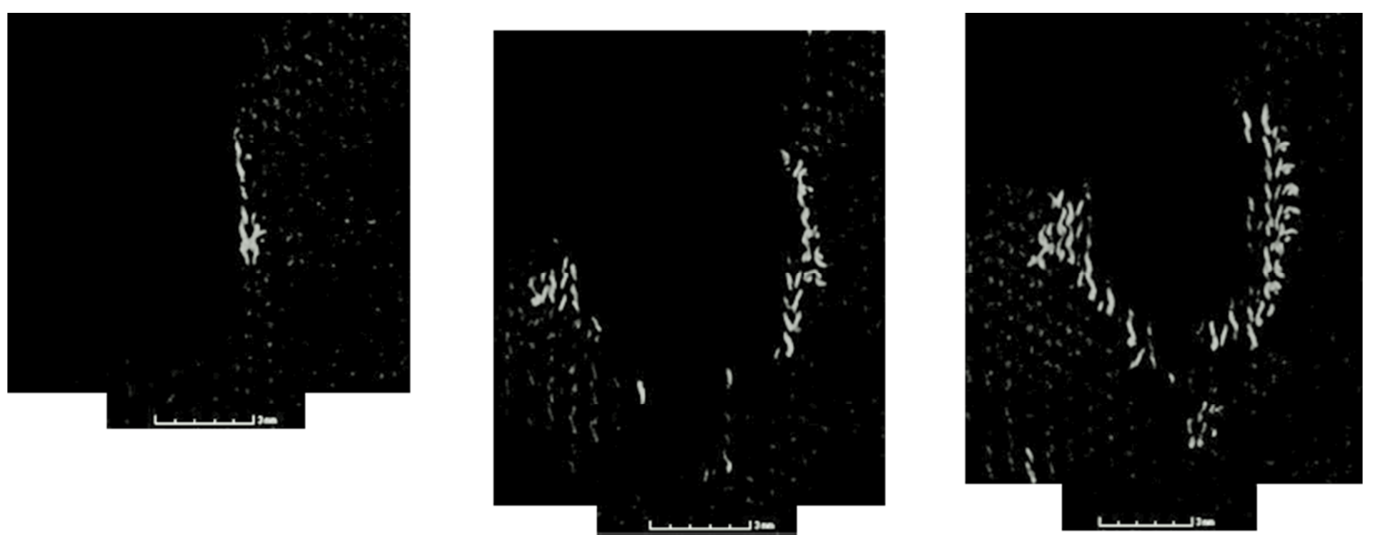

Figure $7 \mathrm{~b}$ : the first three cross-sections in the $\mathrm{z}$-direction for a specimen from $4.5 \mathrm{~ms}^{-1}$
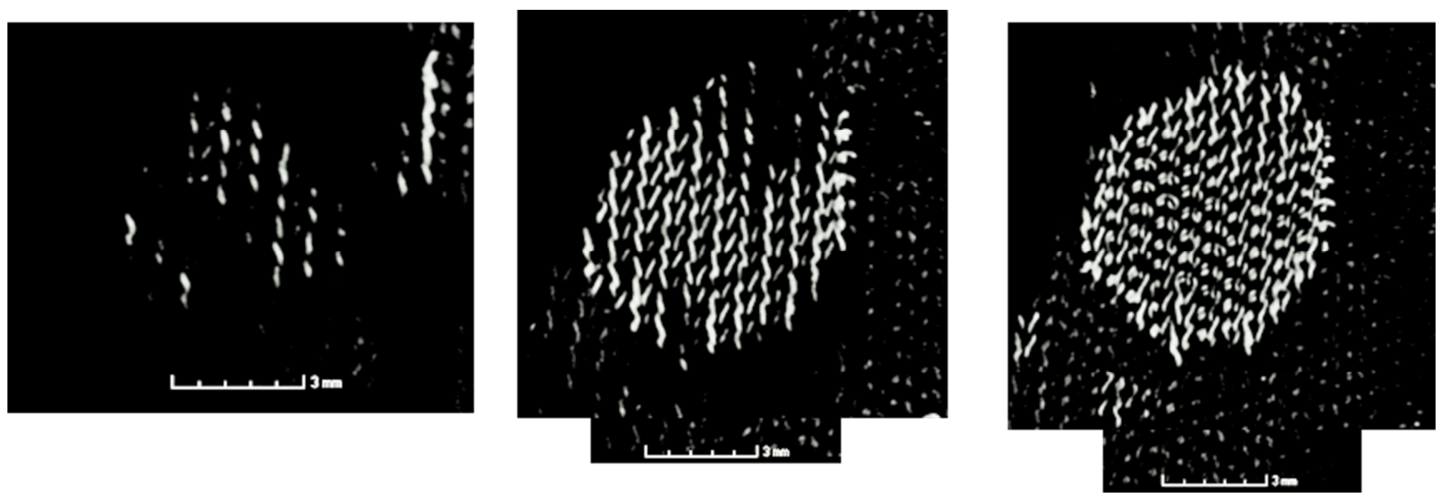

Figure 7c: the first three cross-sections in the z-direction for a specimen from $5.3 \mathrm{~ms}^{-1}$

Figure 7: The first three cross-sections $(0.1 \mathrm{~mm}, 0.2 \mathrm{~mm}$ and $0.3 \mathrm{~mm}$ ) in the z-direction (through the depth of the stain) for a specimen for each velocity for the rib knit fabric.

Bloodstains formed from an impact velocity of $5.3 \mathrm{~ms}^{-1}(1500 \mathrm{~mm})$ had thinner bloodstains $(1 \mathrm{~mm}$ thick) than the other impact velocities. Specimens formed from $4.5 \mathrm{~ms}^{-1}(1000 \mathrm{~mm})$ had the thickest bloodstains $(1.2 \mathrm{~mm})$. Figure 7 shows the first three cross sections for a specimen for all three velocities for the rib knit fabric. From figure $7 a$ and $7 c$ it is possible to see that for the specimens from $3.2 \mathrm{~ms}^{-1}$ and $5.3 \mathrm{~ms}^{-1}$ respectively, the bloodstain has largely formed by a depth of $0.2 \mathrm{~mm}$; there is blood apparent over the vast majority of the area which will be covered when the bloodstain 
reaches its maximum extent. However, figure $7 \mathrm{~b}$ shows the specimen from $4.5 \mathrm{~ms}^{-1}$ has not formed to as great an extent as the other two specimens within that same depth. In figure $7 \mathrm{~b}$, for all three cross-sections, blood is only visible around the edge of the stain, suggesting these sections are therefore raised above the external visible stain.

For the drill fabric (figure 5, 6b) a different pattern was observed. The largest mean area was at the same distance $(0.4 \mathrm{~mm})$ from the technical face for the specimens from the middle impact velocity of $4.2 \mathrm{~ms}^{-1}(1000 \mathrm{~mm})$ and the fastest impact velocity of $5 \mathrm{~ms}^{-1}$. The largest mean area for the slowest impact velocity of $2.9 \mathrm{~ms}^{-1}(500 \mathrm{~mm})$ was seen at a greater depth $(0.5 \mathrm{~mm})$.

The bloodstains formed at a velocity of $4.2 \mathrm{~ms}^{-1}$ produced the largest mean areas in the first two cross sections from the technical face. The area was around $40 \%$ greater than the other two velocities at a depth of $0.1 \mathrm{~mm}$, and between $10 \%$ and $30 \%$ greater at a depth of $0.2 \mathrm{~mm}$, although the large CV at these depths (between $33 \%$ and $58 \%$ ) negates some of this variability. Towards the middle of the bloodstain in the z-direction (between a depth of $0.3 \mathrm{~mm}$ and $0.7 \mathrm{~mm}$ ) the bloodstains from $5.0 \mathrm{~ms}^{-1}$ produced the largest areas, although at most they were only $15 \mathrm{~mm}^{2}$ greater than the areas for the other two velocities. The differences among the areas were greater towards the technical rear of the fabric; the specimens created from the middle velocity of $4.2 \mathrm{~ms}^{-1}(1000 \mathrm{~mm})$ produced the smallest mean area at a depth of $0.7-1 \mathrm{~mm}$.

Univariate ANOVA was undertaken on the first area on the technical face, the maximum area and the last area at the technical rear of the cross-sections in the z-direction. ANOVA revealed only one statistically significant difference due to impact velocity. This was for the area of the cross-section on the technical face for the knit fabric $\left(F_{2,11}=5.523, p=\leq 0.05\right)$. Tukeys HSD analysis revealed a significant difference between only two of the means; $4.5 \mathrm{~ms}^{-1}\left(2.7 \mathrm{~mm}^{2}\right)$ and $5.3 \mathrm{~ms}^{-1}\left(6 \mathrm{~mm}^{2}\right)$. No significant difference was found between either of these two means and the mean area of the bloodstain formed at $3.2 \mathrm{~ms}^{-1}\left(5.4 \mathrm{~mm}^{2}\right)$.

For the bloodstain area formed on the technical face of the drill fabric the data was transformed as it was not normal $(\log 10)$, but no significant difference was found $\left(\mathrm{F}_{2,12}=3.803, p=\mathrm{NS}\right)$. No significant difference was found for the maximum bloodstain area (knit: $\mathrm{F}_{2,11}=1.66, p=\mathrm{NS}$; drill: $\mathrm{F}_{2,12}=2.088, p$ $=N S$ ) or the area of the last bloodstain cross-section at the technical rear (knit: $F_{2,11}=0.454, p=N S$; drill: $\mathrm{F}_{2,12}=0.058, p=\mathrm{NS}$ ).

\section{Warp and wale measurements}

Figure 8 shows the mean and standard deviation of measurements taken in the y (wale or warp) and $x$ (course or weft) directions for the largest cross-section in the z-direction for each of the three impact velocities for each fabric. The coefficient of variation is largest for the $\mathrm{x}$ (weft) measurements for the bull drill, and smallest for the $y$ (warp) measurements for this same fabric. For the rib knit the $\mathrm{CV}$ was similar for both the $\mathrm{x}$ (course) and $\mathrm{y}$ (wale) measurements. A greater difference between the $x$ and $y$ measurements is seen for the bull drill fabric, as well as a suggestion of a pattern, with the $x$ (weft) measurement decreasing with impact velocity and the y (warp) measurement increasing. 


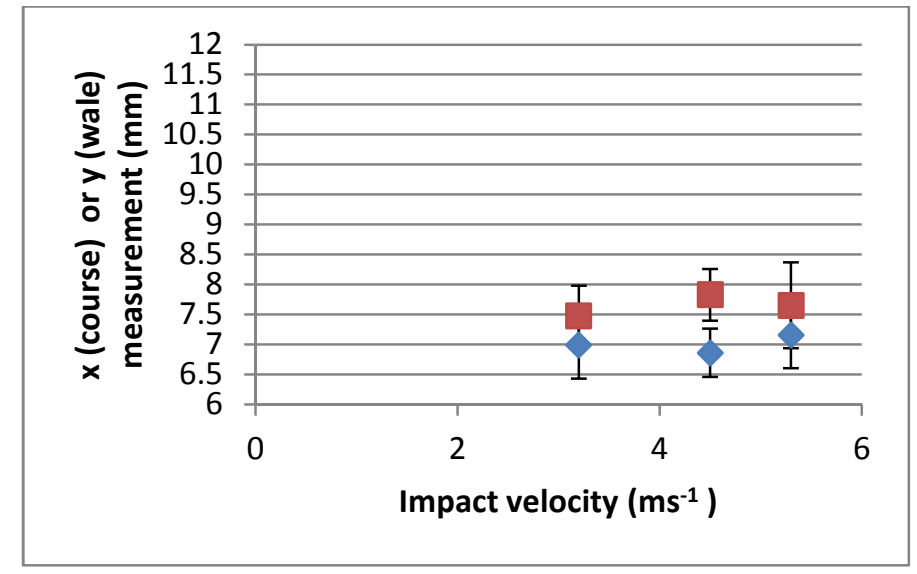

Figure 8a: the mean and standard deviation $\mathrm{x}$ (course) $(\bullet)$ and $\mathrm{y}($ wale) $(\square)$ measurement for each impact velocity for the rib knit fabric

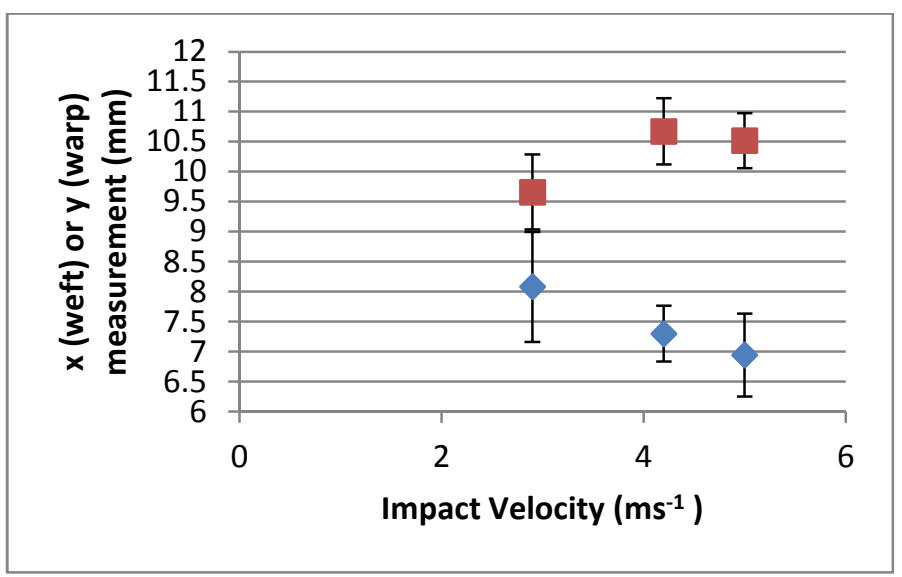

Figure 8b: the mean and standard deviation $\mathrm{x}$ (weft) ( $\diamond$ ) and y (warp) ( $\square$ ) measurement for each impact velocity for the bull drill fabric.

Figure 8: the mean and standard deviation measurements for rib knit and bull drill fabrics for all velocities for the $\mathrm{x}$ (course or weft) and $\mathrm{y}$ (wale or warp) measurements from the cross section with the largest area.

Impact velocity did not affect either the $y$ (wale) or $x$ (course) measurements for the rib knit fabric (wale: $F_{2,11}=0.512, p=N S$; course: $F_{2,11}=0.38, p=N S$ ). For the drill fabric, impact velocity affected the y (warp) measurement $\left(F_{2,12}=4.911, p=\leq 0.05\right)$. Tukeys HSD analysis revealed a significant difference between only two of the means; $2.9 \mathrm{~ms}^{-1}(9.7 \mathrm{~mm})$ and $4.2 \mathrm{~ms}^{-1}(10.7 \mathrm{~mm})$. No significant difference was found between either of these two means and the mean y (warp) measurement from $5 \mathrm{~ms}^{-1}(10.5 \mathrm{~mm})$. Impact velocity did not affect the $\mathrm{x}$ (weft) measurement $\left(\mathrm{F}_{2,12}=3.307, p=\mathrm{NS}\right)$. 


\section{Discussion}

Four key points were examined in this paper: (1) the use of the CT scanner to study bloodstains, (2) the shape of the bloodstain (3) the effect of impact velocity on the bloodstain (4) the effect of fabric structure on the bloodstain.

\section{The use of the CT scanner}

Gaining a greater understanding of the morphology of a bloodstain on fabric has proved difficult by examining the external parent stain (e.g. de Castro et al. 2013). The use of the micro CT scanner has enabled the internal morphology of the bloodstain to be examined, by showing the shape which the blood forms within the fabric and therefore indicating how the blood has moved through the fabric.

\section{Shape of the blood stain}

For all impact velocities and both fabrics the combination of wetting and wicking resulted in a diamond shaped stain. The cross-sectional area of the bloodstain initially increased with depth, before decreasing towards the rear of the fabric. When the blood initially hit the fabric it spread, wetting the top of the fabric and allowing wicking to occur. The largest cross-sectional area was always below the technical face of the fabric (figures 4 and 5). In all cases the largest cross-sectional area was always within $0.5 \mathrm{~mm}$ of the first cross-section of the bloodstain.

For the rib knit fabric, the first cross-sectional area measured was always less than the cross sectional area of the original blood drop (e.g. for an impact velocity of $3.2 \mathrm{~ms}^{-1}$ the mean crosssectional area of the stain was $5.44 \mathrm{~mm}^{2}$ for a blood drop diameter of $4.1 \mathrm{~mm}$ giving a cross-sectional area of the droplet of $13.2 \mathrm{~mm}^{2}$ ). This could also be as a result of the 'coffee ring' effect (as shown in figure 7), whereby the edges of the stain where the particulates have built up above the stain. This section is therefore seen in an earlier cross section than the remainder of the stain.

The mass of the remaining drop resulted in capillary action through the depth of the fabric, which did not occur around the extremities. In figures 4, 5 and 6 this is shown as the gradually decreasing area towards the technical rear of the fabric; as the blood travelled towards the technical rear, there was less liquid to spread.

\section{Effect of impact velocity and fabric type}

Previous studies on absorbent surfaces have suggested that the impact velocity does not affect the surface morphology of bloodstains when the drop size remains constant (e.g. de Castro 2013). In this work there were some suggestions of variability among the impact velocities for the two fabrics. The shape of the bloodstain through the fabric thickness (figures 4 and 6a) varied with velocity for the rib knit fabric. The cross-sectional areas for the fastest $\left(5.3 \mathrm{~ms}^{-1}\right)$ velocity reached their greatest extent closer to the technical face of the fabric than the middle velocity $\left(4.5 \mathrm{~ms}^{-1}\right)$. The first cross-sectional area for the fastest velocity $\left(5.3 \mathrm{~ms}^{-1}\right)$ was only marginally smaller than the cross-sectional area of the original blood drop $\left(10.7 \mathrm{~mm}^{2}\right.$ compared to $\left.13.2 \mathrm{~mm}^{2}\right)$. Both of these findings were most likely due to the higher velocity forcing the blood through the capillaries between and among the yarns and fibres, not allowing much blood to remain on the surface. The faster velocity resulted in a bloodstain which had a larger maximum cross-sectional area, but penetrated a shorter distance into the fabric resulting in a shallower depth, suggesting sideways wicking is dominating at this velocity. 
The middle velocity $\left(4.5 \mathrm{~ms}^{-1}\right)$ resulted in the smallest maximum area. It also had the deepest maximum area, $0.5 \mathrm{~mm}$ compares to $0.4 \mathrm{~mm}$ for the $3.2 \mathrm{~ms}^{-1}$ and $5.3 \mathrm{~ms}^{-1}$ impact velocities. This suggests sideways wicking was less dominant at this velocity, allowing more capillary action. However, why the lowest velocity $\left(3.2 \mathrm{~ms}^{-1}\right)$ had a maximum area only $1 \mathrm{~mm}^{2}$ smaller at the same depth into the fabric as the highest velocity $\left(5.3 \mathrm{~ms}^{-1}\right)$ raises further questions. The lowest velocity may have allowed the blood to wick to a greater extent than the middle velocity.

A statistically significant difference was seen between the areas on the technical face of the rib knit fabric for the specimens from $4.5 \mathrm{~ms}^{-1}$ and $5.3 \mathrm{~ms}^{-1}$. This pattern was not observed for the maximum area or the technical rear, indicating the greatest differentiation between these two groups of specimens was present on the technical face of the fabric. This was not a differentiation seen in the original external analysis of the parent stain (de Castro et al. 2013) as the technical face area measurement from the $\mathrm{CT}$ cross-sections was different to the area of the visible parent stain on the external surface. This can be seen in figure 7 , in that the bloodstain in the first cross-section for all three specimens is only a small percentage of the maximum area of the bloodstain, and the external visible stain. This is something which would not have been visible in the original external analysis of the bloodstain.

The lack of variability among the cross sectional areas depending on velocity seen in the bull drill fabric was most likely owing to the smaller capillary spaces than in the rib knit fabric. This meant the blood could not dissipate to a great extent regardless of the velocity (Kissa 1996). However, a statistically significant difference was seen in the warp measurement of the bloodstain for the bull drill fabric (figure 8b) for specimens from $2.9 \mathrm{~ms}^{-1}$ and $4.2 \mathrm{~ms}^{-1}$. These measurements were taken from the largest cross-section in the z-direction; however, the area measurements of this same cross-section revealed no statistically significant differences. This suggests that it is the warp measurement which varies most with velocity for this fabric. The pattern which is seen in figure $8 \mathrm{~b}$, where the weft decreased as the warp increased, helped explain why there was no statistically significant difference in the areas for the bull drill. As the warp was increasing as the weft decreased, the area would remain approximately similar throughout. However, no significant difference was seen among the weft measurements, most likely owing to the greater $\mathrm{CV}$, pointing to the fact that the variation among specimens within a velocity was greater than for the warp measurement.

\section{Conclusions}

This pilot study has demonstrated that micro CT scanning may aid understanding of the morphology of bloodstains on and within fabrics. The technique has allowed extra measurements to be taken regarding the size and shape of the bloodstain inside the fabric. The results have shown that the maximum cross-sectional area occurs below the surface of the fabric and the stain therefore formed a diamond shape within the fabric as a result of wetting and wicking occurring.

This work has identified some variability regarding the bloodstain morphology on two common fabrics due to impact velocity, for example the variation in the area of the cross-sections throughout the depth of the stain. This work has also suggested that the structure of the fabrics themselves did have an effect on the bloodstain morphology. 


\section{References}

Adam, C. (2012) 'Fundamental studies of bloodstain formation and characteristics', Forensic Science International 219, 76-87.

Bevel, T. and Gardner, R. M. (2008) Bloodstain pattern analysis with an introduction to crime scene reconstruction. Florida: CRC Press.

Crow, R. and Osczevski, R. (1998) 'The Interaction of Water with Fabrics', Textile Research Journal 68 (4), 280-288.

de Castro, T. C., Nickson, T., Carr, D. J. and Knock, C. (2013) 'Interpreting the formation of bloodstains on selected apparel fabrics', International Journal of Legal Medicine 127, 251-258.

de Castro, T. C., Taylor, M. C., Kieser, J. A., Carr, D. J. and Duncan, W. (2015) 'Systematic investigation of drip stains on apparel fabrics: The effects of prior-laundering, fibre content and fabric structure on final stain appearance', Forensic Science International 250, 98-109.

Deegan, R. D., Bakajin, O., Dupont, T. F., Huber, G., Nagel, S. R. and Witten, T. A. (1997) 'Capillary flow as the cause of ring stains from dried liquid drops', Nature 389, 827-829.

Hulse-Smith, L., Mehdizadeh, N. and Chandra, S. (2005) 'Deducing drop size and impact velocity from circular bloodstains', Journal of Forensic Science 50, 1-10.

Hulse-Smith, L. and Illes, M. (2007) 'A blind trial evaluation of a crime scene methodology for deducing impact velocity and droplet size from circular bloodstains', Journal of Forensic Science 52, 65-69.

Indiana v. David Camm, 812 N.E.2d 1127 (Ind. App., 2004).

Karger, B., Rand, S. and Brinkmann, B. (1998) 'Experimental bloodstains on fabric from contact and from droplets', International Journal of Legal Medicine 111, 17-21.

Karger, B., Rand, S., Fracesso, T. and Pfeiffer, H. (2008) 'Bloodstain pattern analysis: casework experience', Forensic Science International 181, 15-20.

Kissa, E. (196) 'Wetting and Wicking', Textile Research Journal 66, 660-668.

Knock, C. and Davidson, M. (2007) 'Predicting the position of the source of blood stains for angled impacts', Journal of Forensic Science 52, 1044-1049.

Laing, R. M., Niven, B. E., Barker, R. L., and Porter, J. (2007) 'Response of Wool Knit Apparel Fabrics to Water Vapour and Water' Textile Research Journal 77 (3), 165-171. 
Metris (2008) CT Pro User Manual.

Nikon Metrology (2010) 'X-Ray and CT Technology for Industrial Applications'. http://www.nikonmetrology.com/en EU/Products/X-ray-and-CT-Inspection/Computed-

Tomography/XT-H-225-Industrial-CT-Scanning/(brochure) (Page consulted $22^{\text {nd }}$ January 2015).

Patnaik, A., Rengasamy, R. S., Kothari, V. K. and Ghosh, A. (2006) 'Wetting and Wicking in Fibrous Materials', Textile Progress 38 (1), 1-105.

Schneider and Holcombe (1988) 'The role of radiation in fabric warmth' in G. A. Carnaby, E. J. Wood and L. F. Story (eds) Advanced workshop on the application of mathematics and physics in the wool industry proceeding. 488-502. New Zealand: Lincoln.

Scientific Working Group on Bloodstain Pattern Analysis (2014) 'Recommended Terminology' http://www.swgstain.org/resources (Page consulted 22nd January 2015).

Volume Graphics (2014) 'VGStudio Max 3.0' http://www.volumegraphics.com/products/vgstudiomax/basic-functionality/ (Page consulted $22^{\text {nd }}$ January 2015)

White, B. (1986) 'Bloodstain patterns on fabrics: the effect of drop volume, dropping height and impact angle', Canadian Society of Forensic Science Journal 19, 3-36. 